\title{
Denial of pregnancy: population based study
}

\author{
Jens Wessel, Ulrich Buscher
}

Department of Obstetrics, Charité, Campus

Virchow-Klinikum,

Humboldt-University,

13353 Berlin,

Germany

Jens Wessel

senior lecturer

Ulrich Buscher

senior lecturer

Correspondence to:

U Buscher

ulrich.buescher@

charite.de

BMJ 2002;324:458
The prevalence of denial of pregnancy, a woman's lack of awareness of being pregnant, is not reliably known. Few studies describe large numbers of cases, ${ }^{12}$ but descriptions of 27 and 28 patients at a single obstetric hospital led to estimates of one denied pregnancy in 300-600 pregnancies. ${ }^{3}$ However, these numbers were determined within a more or less random observation period and are lacking an epidemiological relevance.

\section{Methods and results}

Between 1 July 1995 and 30 June 1996 we asked all 19 obstetric hospitals and five obstetrics and midwives' practices in the Berlin metropolitan area to report cases of women who were not aware of being pregnant and did not have a doctor's diagnosis of pregnancy during the first 20 weeks, or more, of gestation.

Altogether 62 women did not realise they were pregnant until after 20 weeks' gestation. On the basis of 29462 deliveries during the study period, we determined that 1 in 475 (95\% confidence interval 370 to $625)$ pregnancies were denied by the woman.

In 37 women pregnancy was diagnosed before the birth; in the remainder, the diagnosis was made during labour. In 12 deliveries ( 1 in 2455 (1429 to 5000) births) a viable fetus was born without the woman having realised that she was pregnant until she went into labour.

\section{Comment}

The common view that denied pregnancies are exotic and rare events is not valid. Deliveries in which the woman has not been aware of her pregnancy until going into labour occur about three times more often than triplets (1:7225, Hellin rule). Denial of pregnancy at 20 weeks of gestation, or later, occurs more often than rhesus haemolytic disease (1:1000 since Rhesus prophylaxis has become available) or a uterine rupture (1:1500). Denial of pregnancy may put both mother and fetus at risk. ${ }^{5}$
The ratio of one denied pregnancy in 475 births is based on complete reporting within a large region (all births in Berlin metropolitan area during one year) and is representative for the total population of a German federal state. In all of Germany in 1995 and 1996 there were about 770000 deliveries per year; on this basis we calculate that in about 1600 births the mother would not have been aware of her pregnancy at 20 weeks of gestation, or later-and each year 300 women would not have realised they were pregnant until going into labour.

As the completeness of recruited cases could not be determined, the true rate may be even higher. Also, though cases were determined prospectively, the period of "non-awareness" was determined from information supplied by the woman after she became aware of her pregnancy.

It cannot be stated whether the results are generally applicable outside of Berlin. However, ratios determined earlier for a small German city of Celle (1:357), ${ }^{2}$ and for Berlin (1:275-586), ${ }^{4}$ compare to those in this study. Furthermore, a ratio of $1: 400$ in the large Austrian city of Innsbruck indicates a comparable frequency of denial of pregnancy across different sociodemographic regions. ${ }^{3}$

Contributors: JW was responsible for study design and conduct, data analysis, and writing of the report. UB participated in analysing the data and writing of the paper. JW is the guarantor. Funding: We thank the German Research Foundation (Deutsche Forschungsgemeinschaft) for a habilitation grant to JW. Competing interests: None declared.

1 Milden R, Rosenthal M, Winegardner J, Smith D. Denial of pregnancy: an exploratory investigation. J Psychosom Obstet Gynecol 1985;4:255-61.

2 Brych Ch. Verdrängte Schwangerschaft: eine Analyse von Beobachtungen der Jahrgänge 1990 und 1991 [dissertation]. Hanover: Medical University, 1994 .

3 Brezinka C, Huter O, Biebl W, Kinzl J. Denial of pregnancy: obstetrical aspects. J Psychosom Obstet Gynecol 1994;15:1-8.

4 Wessel J, Rau G. Zur Schwangerschaftsverdrängung-Darstellung eines Phänomens anhand einiger Ergebnisse von 28 Fällen und Vorstellung einer prospektiven regionalen Verbundstudie für Berlin. Geburtsh Frauenheilk 1997:57:116-23.

5 Spielvogel AM, Hohener HC. Denial of pregnancy: a review and case reports. Birth 1995;22:220-6.

(Accepted 10 December 2001)

\section{One hundred years ago \\ The sanitary condition of the house}

On Friday night last week, after a long debate on congested districts in Ireland, about 11 o'clock, Mr. Wylie, who does not often trouble the House, rose to call attention to the imperfection of the ventilation and other sanitary arrangements. The hon. member was full of his subject; he discoursed learnedly on electric fans and on the old-fashioned and obsolete method by which the chamber was ventilated, and still worse, the galleries in which the reporters were stupefied by bad air and the ladies almost asphyxiated. The House was in a nonchalant mood and would barely listen. Members were tired and saw a chance of soon going away till Monday, and they would not take the subject seriously. The more the hon. member dilated on fresh air and bad lavatories the more the House smiled; and when he came to microbes the smile broadened and became a roar of delighted laughter as he declared that the microbe of lockjaw had been found in a piece of carpet taken from a legislative chamber in America! He asked for a committee of experts, and said better ventilation would do more for comfort than the new rules of procedure. The First Commissioner of Works made a good-natured reply, and said he intended to move for a committee before Easter, and he would consider whether it should be composed of experts or be a Select Committee of the House. The air was frequently taken and analysed, and a specimen was at present in process of analysis. The matter then dropped and the House rose at 11.30 .

(BMJ 1902;i:736) 